\title{
Information Structure of the Utterances Spoken by Children with Mental Retardation: A Case Study on Ansyah
}

\author{
Mulyono \\ Universitas Negeri Surabaya \\ Surabaya, Indonesia \\ mulyono@unesa.ac.id
}

\author{
Agus Subiyanto \\ Universitas Diponegoro \\ Semarang, Indonesia \\ subaling@gmail.com
}

\author{
Prima Vidya Asteria \\ Universitas Negeri Surabaya \\ Surabaya, Indonesia \\ primaasteria@unesa.ac.id
}

\begin{abstract}
Children with mental retardation (CMR) have the language characteristic of using inappropriate language rules, incomplete, simple, and short constructions, and a lot of deletions. To be able to grasp the meaning of the CMR speech, some additional situational information is needed. This study aims to reveal the phenomenon of information structure patterns found in the CMR's spoken utterances. The data used were taken from the utterances spoken by a child with mental retardation obtained through an observation method with a recording and an elicitation technique. The results show that Subject in CMR's speech often has the function as the Topic. In this case, Topic is not the same as Subject (SUBJ) because Topic is a pragmatic relation, while Subject is a grammatical relation. As old information, Topic in a sentence is often wiped out. Topic sometimes becomes an internal part of a sentence and sometimes it is outside the internal structure of sentences. Both variants were found in CMR's speech. The formation of the discourse functions, such as Topic, Focus, and Background Information (BI) in a sentence causes a different pattern of information structure (i-str). The variations of i-str patterns found in CMR's speech are (1) Topic + Focus, (2) Topics + Focus + BI, and (3) Focus only. Of the three patterns it appears that Focus is always present in the sentence because without Focus the sentence becomes less informative. In contrast, Topic and BI may be present or absent in a sentences.
\end{abstract}

Keywords - language patterns, information structure, children with mental retardation

\section{INTRODUCTION}

Children with mental retardation (CMR) are children with limited intellectual ability and weak memory resulting in a language deficit. CMR generally has a moderate deficit of language in all aspects of language ranging from phonology, morphology, to syntax.
When viewed from the characteristics of word order patterns, the CMR language has an opposite pattern to that of the normal pattern (reversed word-order pattern) either in the phrase or clause or sentence they produce. The variation of the often reversed pattern in CMR speech is interesting to examine because it is motivated by the lack of dominance of the syntactic rules that they should have mastered. The results of previous studies have proved that there is a close correlation between the sequence pattern with the pragmatic

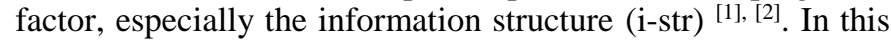
case, Topics and Focus as two primary information entities that exist in a proposition are considered to have a very important role in determining the sequence pattern in the sentence.

When viewed from the characteristics of the completeness of its elements, the CMR language has many similarities with the language of dyslexic children ${ }^{[3]}$, [4], such as the frequent use of deletions and very simple and short constructions. The phenomenon of language with such characteristics can be explained comprehensively through parallel structural analysis based on lexical functional grammar (LFG) theory.

According to the LFG theory ${ }^{[5]}$, in a syntactic construction there are several layers of structure which include the constituent structure (c-str), the grammatical function structure (f-str), the argument structure (a-str), the semantic structure (s-str), and the information structure (i-str). Each of these structural layers can be represented individually and can also be mapped in parallel projections. As for the characteristics of the data, this study focuses on the information structure (i-str).

I-Str is a part of a syntactic study, especially with regard to pragmatic aspects. The concept of $i$-str in this study was taken from Lambrecht ${ }^{[6]}$ stating that $i$-str is a part of a sentential grammar in which there is a proposition as a conceptual representation of the state, paired with the lexico-grammatical 
structure in relation to the mental state a speech imprint that uses and interprets the structure as an information unit within the context of a particular discourse. This concept implies that $\mathrm{i}$-str is in the sentence level, and i-str is determined by the kind of proposition of the constituent contained in the sentence.

I-str is determined on the basis of pragmatic relation, i.e the relative relationship between the proposition and the elements that make up the sentence. According to Gundell ${ }^{[8]}$, pragmatic relations are divided into two discourse functions, namely Topics and Commentaries. Vallduvi ${ }^{[7]}$ uses the term Ground and Focus to refer to the two functions of the discourse, while Lambrecht ${ }^{[6]}$ uses the terms Topic and Focus for these functions. From the synthesis of the three pairs of terms, this study uses three terms to refer to the functions of discourse, namely Topic (TOP), Focus (FOC), and Background Information (BI).

\section{METHOD}

This research is descriptive-qualitative with a naturalistic model. The data were taken from natural CMR's speech. The data were collected using an observation method with audio and video recordings, as well as an elicitation. The subject of this study was a child aged 7 years (Hypothesis of Critical Age) with mild mental retardation, speaking Indonesian as the first language. The main instrument is the researcher using guided references on elicitation techniques, tape recorder, and stationery. The data analysis was done by identifying data stages, selecting data, coding data, classifying data, and analyzing data. The results of analysis are presented using formal and informal methods.

\section{RESULT AND DISCUSSION}

I-str is the structure of the semantic content in a sentence (speech). I-str is composed of three discourse functions, namely TOP, FOC, and BI. The third formation of the discourse functions forms a certain i-str pattern in the sentence structure. Thus, differences in the formation of discourse functions as a result of deletions or alteration of the sequential patterns in sentences can lead to differences in the pattern of istr.

Topic is a term used by Gundell ${ }^{[7]}$ to refer to an entity already in the mind of the listener or the other person. An entity may be a Topic if the speaker assumes that the opponent has a prior knowledge of the entity. The concept of Topic was then developed by Lambrecht ${ }^{[6]}$ by incorporating aspects of discourse. According to Lambrecht ${ }^{[6]}$, Topic is determined by a context or situation. Therefore, it is difficult to determine the Topic in a loose sentence.

The term 'Focus' refers to the information affirmed in the sentence. Focus is a semantic component of a pragmatically structured proposition to express affirmation and not presupposition ${ }^{[6]}$. The discourse function of Focus must be present in the sentence to make the sentence information clear. Lambrecht ${ }^{[5]}$ devided Focus into broad focus and narrow facus. Broad Focus can be the Focus on a sentence and the Focus on predicates, while Narrow Focus, also called argument Focus, has a domain limited to certain single constituents such as Subject, Object, Adjunc, or Auxiliari (markers of Tense, Aspectuality, and Modality). Both types of focus can be found in CMR sentences (speech).

The term Background Information (BI) has similarities to Topic, as both of which refer to old information or information that is already known from the previous context. However, BI is different from Topics because Topics are pointers of relevant information that have been known before by the listeners. In contrast, BI is just additional old information used to indicate that there will be new information (Focus) in the sentence.

According to Subiyanto ${ }^{[9]}$, in the Javanese language, BI can appear in sentences with argument Focus. Mulyono's [3] results also show that BI also appears in the speech of dyslexic children. In a sentence spoken by CMR, BI also appears though very rarely. In responding to a sentence, for example, the CMR usually directly mention the Focus constituent and tend to dissolve the BI. However, BI constituents sometimes appear as in the following sentence.

(1a) Ansyah kenapa diam saja?

(2a) Ansyah mau ya?

(3a) Ansyah mau apa?

(3b) Mau itu.

$[\mathrm{Mau}]_{\text {BI }}[\mathrm{itu}]_{\text {FOC }}$ (itu= mainan mobil-mobilan)

In sentence (1a) and (2a), the speaker has been asked twice but she remains silent. The third question of the new speaker (3a) was responded by Ansyah as a speaker. In the third question, the part in question is information that serves as a complement to the verb. The response to the question, which is sentence (3b), states that the information affirmed is the Focus. The focus in this utterance comes along with the verb mau 'wanted' which is the old information as well, as it has been mentioned in the previous sentence. As the old information, the verb in (3b) is BI. The existence of the verb here provides additional information that serves to connect new information with the old information, ie Ansyah, in this case as the Topic. This structure can be described in diagram 1 below.

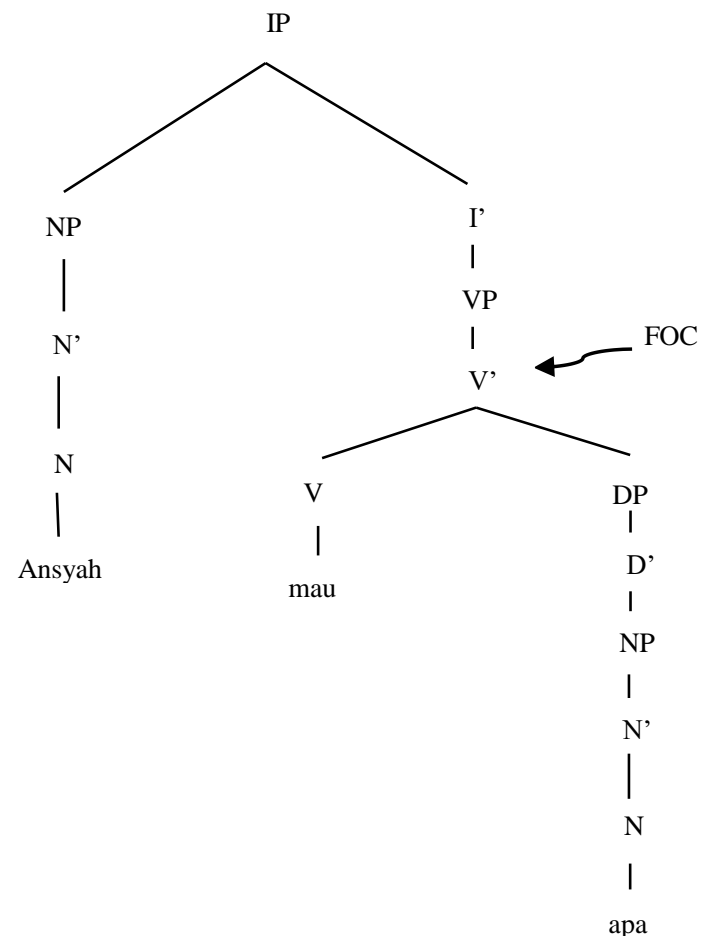




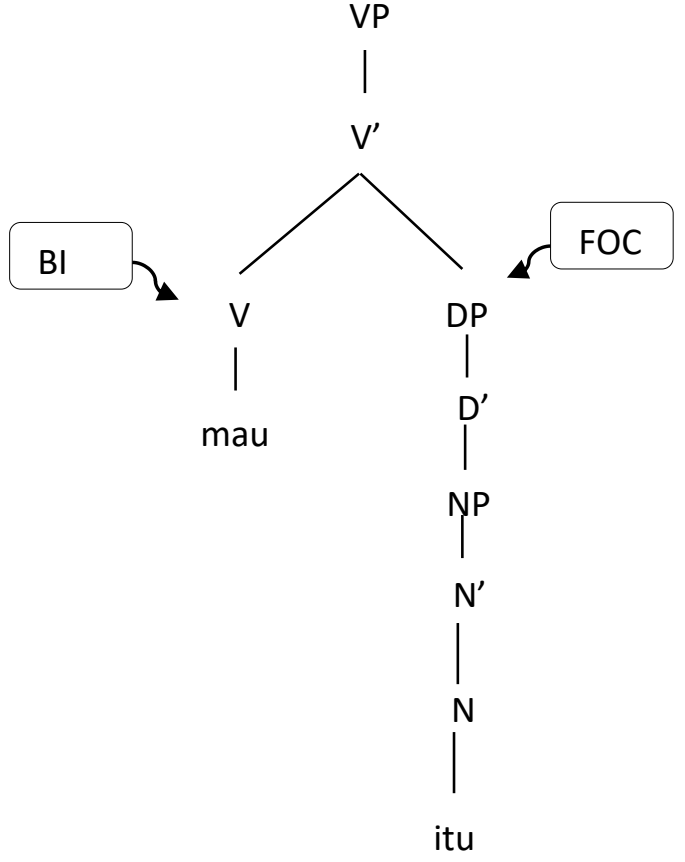

Diagram 1. Correspondence c-str and i-str

In diagram 1 above, the speaker's answer is BI and the complement is the Focus. The following diagram illustrates the information structure of the question-answer utterances.

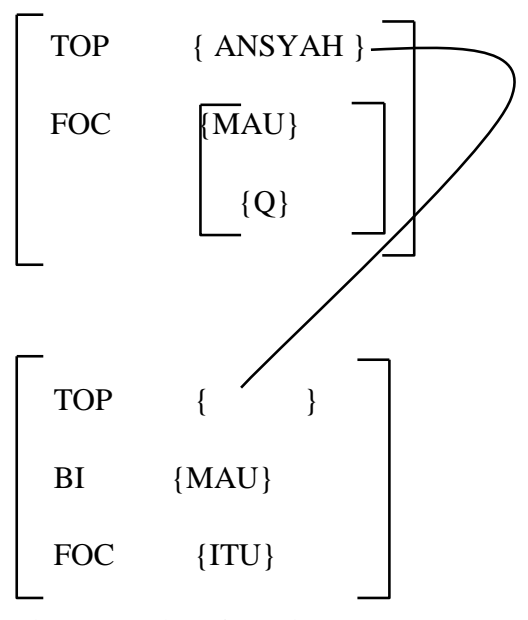

Diagram 2. The Information Structure

The three functions of the above discourse, namely Topic, Focus, and BI, rarely appear completely in CMR sentences. Because of the frequent deletion cases of constituents, the structure of CMR sentences more often consists of Topic and Focus only, BI and Focus only, or even Focus only. In this case Focus must be present in the sentence because of its existence to support the clarity of sentence information. In contrast, Topic and BIs are sometimes present and sometimes absent (due to the constituent deletion) because their existence is optional. On the basis of the presence or absence of this function of the discourse, the sentences in the CMR's speech can be classified into three patterns of information structure, ie (1) Topic-Focus patterns, (2) Focused sentence patterns, and (3) Topic-Focus-BI patterns ${ }^{[10]}$

The Topic-Focus pattern can occur in sentences with Subjects as Topics and Predicates as Focus. The subject of a sentence often has a Topic function. However, the topic here is different from Subject because Topic is a pragmatic relation, while Subject is a grammatical relation. In terms of usingTopic-Focus or Subject-Predicate patterns, the CMR usually ask something related to the actions performed by the Topic or events that occur in the Topic. The Topic-Focus pattern is contained in a question-and-answer sentence with a question sentence that asks the action done by the Topic or states the event experienced by the Topic, whereas the answer sentence confirms the actions done by the Topic or confirms the events occurring on the Topic.

The constructions with the Topic-Focus pattern also encounter Topic deletion phenomenon. Topic deletion occurs if the entity that is the Topic in the sentence also becomes a Topic in a previously sentence or construction. In other words, this phenomenon occurs in constructions containing a continuous topic. However, if there is a Topic change, the Topic function does not occur explicitly .

In a sentence containing only one discourse function, the Focused sentence pattern, all constituents in the sentence function as Focus. This pattern of information structure is often event reporting. This pattern appears in a sentence stating an event that occurs around the CMR.

In CMR spoken words, the Topic-Focus-BI pattern can be found in sentences that have Focus arguments, especially the Object and Adjunc argument functions. In a sentence that has an argument Focus, the constituent that is not part of the Focus is the old information, which can occupy the Topic or BI function. The old information being discussed in sentences and the prominent nature serves as a Topic, while nonprominent ones serve as BI. In this case Topics and BI there are present together with Focus, and some are experiencing the percolation. Despite the perception, the existence of the Topic and the BI remain identifiable from the context of the previous sentence.

To clarify the description, here are some examples of data and analysis diagrams. In the data of sentence (4b)-(5b) below, all sentence components are Focus. Conversely, the passage of the sentence, namely masak and lepas, is a topic. The topic in this case can be traced from the previous sentence, which is in the sentence (4a)-(5a). Since all of the above (4b)-(5b) sentence components occupy the SUBJ function, the structure is called Focus SUBJ. Because it has a domain that is limited to a single constituent of the SUBJ argument, the focus can also be called a narrow facus.

In addition to the Subject Focus, there are several Focus structures that appear in the CMR speech, the Predicate Focus as found in the data (6b)-(7b); Object Focus as found in data (8b)-(9b); and Adjunc Focus as found in the data (10b).

(4a) Siapa yang masak?

(4b) Mama.

(5a) Apanya yang lepas? 
(5b) Kelincinya.

(6a) Di mana papamu?

(6b) Pergi.

(7a) Sedang apa Rudi?

(7b) Baca buku.

(8a) Ansyah suka lihat film apa?

(8b) Upin ipin.

(9a) Kamu bawa apa?

(9b) Robot.

(10a) Kandang kelincinya ditaruh di mana?

(10b) Luar.

(11a) Papamu bekerja di mana?

(11b) Elektronik.

An interesting point that needs to be discussed further is about the phenomenon of deletion contained in the data (8b) and (11b). The response of Upin Ipin's response from CMR to data $8 \mathrm{~b}$ is a very concise, incomplete sentence. Normally, a reasonable answer sentence for a sentence that has this Object Focus is film Upin Ipin 'Upin Ipin Movie'. However, in the CMR's answer the word film 'movie' does not appear and is experiencing the expression as well. Why is that? The logical reason is related to the new information (Focus) in the sentence. In accordance with the context, the new information (Focus) in the sentence is Upin Ipin, while the film becomes old information (BI) so it is dissipated. As the old information, the film in normal speech will appear because it is syntactically a constituent unity, while pragmatically has a function for better understanding of Focus (Upin Ipin). That is why in CMR's speech that appears only Upin Ipin although in reasonable speech will appear film Upin Ipin 'Upin Ipin Movie'. When visualized, the diagram form as diagram 3 below.

a.

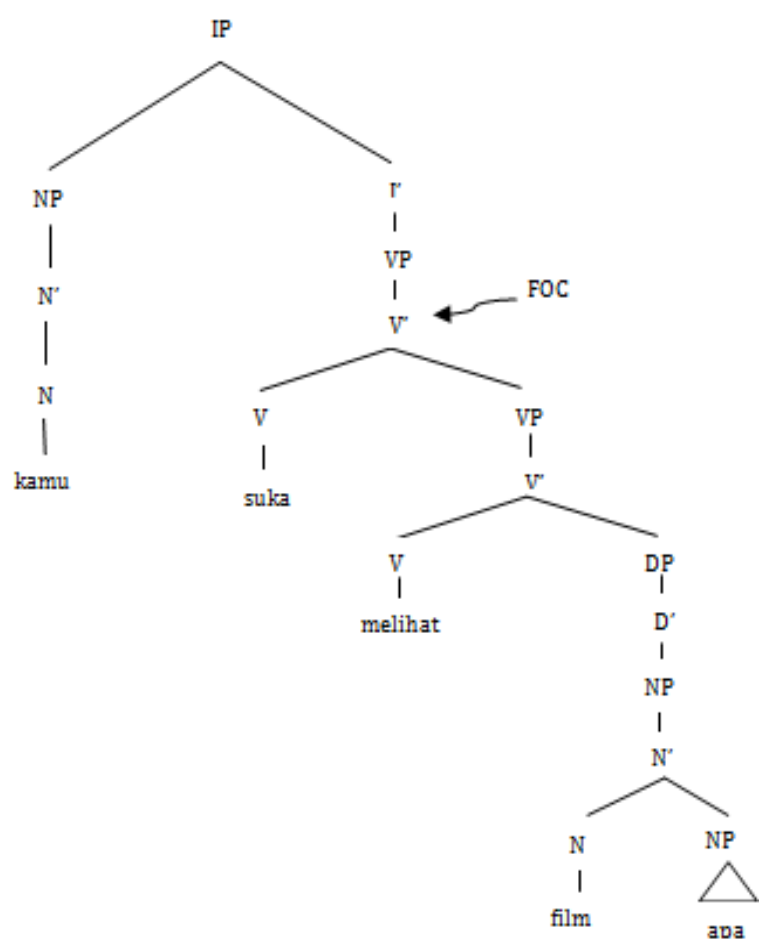

b. (1)
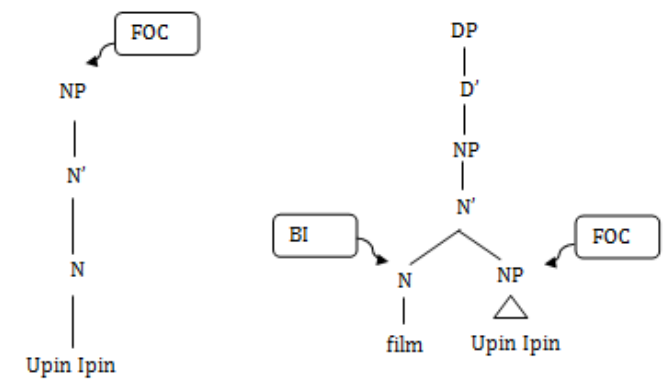

Diagram 3. The Information Structure with The Focus Function

Diagram 3 above shows the answer of the speaker only in the form of information that has the Focus function. When visualized, the information structure looks like the following.

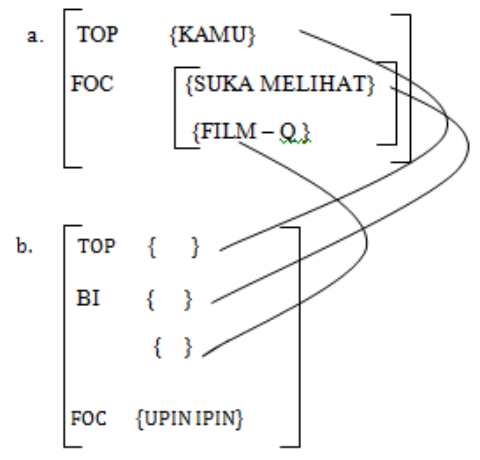

Diagram 4. The Information Structure with The Focus Complement

In contrast, diagram 4 shows the answers of speakers in the form of BI and its complement to Focus. When visualized, the information structure looks like the following.

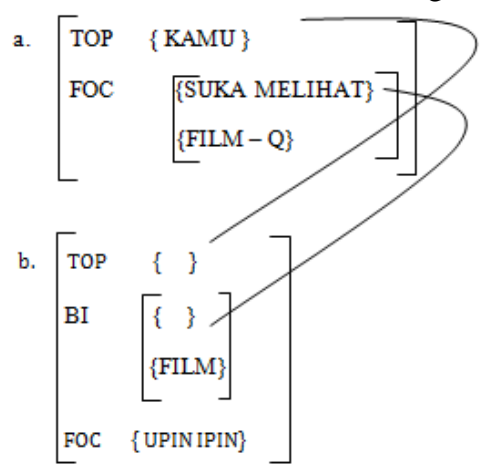

Diagram 5. The Information Structure with The Focus Complement

In the data (11b) above, usually a reasonable answer for a sentence that has this Adjunc Focus is di toko elektronik 'in an electronics store'. Still, the utterances of CMR are elektronik 'electronic'. It can be interpreted in phrase terms as FP by considering the context of the previous sentence. In the CMR's answer, not only is the preposition in which it has been subjected to imprinting, but also one of the noun components that complement FP, ie the shop, is also subjected to exploitation. Why is that? The answer is related to the information in that sentence. Although the prepositions within 
the phrase are actually core, the focus of the information remains on toko elektronik FN 'the electronic store FN' that the CMR wishes to convey. Then, the Focus structure is still focused again on what really becomes the core of the information, namely elektronik 'electronics'. In this case CMR does not care about the completeness of the utterance delivered. What is stated is only what new information is needed by the questioner. That is why the grammatical speech appears unacceptable because it does not meet the completeness of speech. Nevertheless, his speech can still be understood by considering the context.

The phenomenon of CMR sentences that tend to ignore language rules, short, short, simple, and many of the deletions described above can be expressed as very concise structures. It can happen because the data taken comes from oral data. The context of verbal speech requires a second person / speaking partner. In the process, verbal communication is supported by motion, mimic, views, nods, intonations, and situations of speech to understand the message conveyed. Therefore, the core parts of the sentence that occupy grammatical functions such as SUBJ, OBJ, or others are sometimes left off resulting in the disappearance [11].

\section{CONCLUSION}

The concept of i-str in this study refers to Lambrecht ${ }^{[5]}$ stating that $i$-str is a sentence grammatical component in which there is a proposition as a conceptual representation of the state, which is paired with a lexico-grammatical structure in relation to the mental state of exposure talk that uses and interprets the structure as an information unit within the context of a particular discourse. From this concept it appears that $\mathrm{i}$-str is in the sentence level, and is determined by the type of proposition of the constituent contained in the sentence. I-str a sentence is awakened from a pragmatic relation, ie the relative relationship between propositions and the elements that make up the sentence. Pragmatic relations are divided into three discourse functions, namely topics (TOP), focus (FOC), and background information (BI). This study found that subject of a sentence in CMR speech often has the function as the topic. In this case, topic is not the same as subject (SUBJ) because topic is a pragmatic relation, while subject is a grammatical relation. As the old information, the existence of topics in sentences is often wiped out. Topics sometimes become internal parts of a sentence and sometimes they are outside the internal structure of a sentence. Both variants were found in CMR's speech. In cross-linguistic studies, Focus can be realized through prosodies, word order, morphological markers, and syntax markers ${ }^{[9]}$. In CMR's speech, Focus is syntactically realized through a sequence pattern and pragmatically through its context. The different formation of the discourse functions, ie Topics, Focus, and BI in a sentence causes a different pattern of i-str. The variations of i-str patterns found in CMR's speech are (1) topic + focus, (2) topics + focus + BI, and (3) focus only. Of the three patterns Focus is always present in the sentence because without having focus a sentence becomes less informative. In contrast, topics and BI can be present or absent in a sentence.

\section{REFERENCES}

[1] K. Lambrecht, When Subjects Behave Like Objects: An Analysis of The Merging of $\mathrm{S}$ And $\mathrm{O}$ in Sentence-Focus Constructions Across Languages. Studies in Language 24:3, 2000. pp. 611-682.

[2] E.V. Radionova, Word Order and Information Structure in Russian Syntax. Thesis at The University of North Dakota, 2001.

[3] Mulyono, The Variation of Sentence Structure in the Dyslexic Children'sSpeech, 2018.

[4] Mulyono. 2018. Syntactic Simplicity In Dyslexic Children's Utterances. ASSEHR. Antlantis Press. Vol. 108, 2018. pp. 268-272.

[5] M. Butt, M. Dalrymple, and A. Frank, An architecture for linking theory in LFG. Proceedings of the LFG97 Conference. San Diego: University of California, 1997.

[6] K. Lambrecht, Information structure and sentence form: Topic, focus, and the mental representation of discourse referents. In Cambridge Studies in Linguistics 71. Cambridge: Cambridge University Press, 1994.

[7] J.K. Gundel, The Role of Topic and Comment in Linguistic Theory: Outstanding Dissertations in Linguistics. New York: Garland, 1988.

[8] E. Vallduvi, The Informational Component. IRCS T echnical Reports Series. 188. University of Pennsylvania, 1993.

[9] A. Subiyanto, Predikat Kompleks Bahasa Jawa: Kajian Sintaksis dan Pragmatik. Dissertation. Denpasar: Universitas Udayana, 2013.

[10] Mulyono, Struktur Informasi dalam Tuturan Anak Disleksia, 2016.

[11] E. Z. Arifin, and S. A. Tasai, Cerdas Berbahasa Indonesia Untuk Perguruan Tinggi, Aka press, 2010. 